\title{
GHG Performance Evaluation in Green Deal Context
}

\author{
Beate ZLAUGOTNE ${ }^{1 *}$, Linda IEVINA ${ }^{2}$, Reinis AZIS ${ }^{3}$, Denis BARANENKO ${ }^{4}$, \\ Dagnija BLUMBERGA ${ }^{5}$ \\ 1-3,5 Institute of Energy Systems and Environment, Riga Technical University, \\ Azenes iela 12/1, Riga, LV-1048, Latvia \\ ${ }^{4}$ Institute of Refrigeration and Biotechnologies, ITMO University, Lomonosova street 9 , \\ Saint-Petersburg, 191002, Russian Federation
}

\begin{abstract}
Recently introduced European Green Deal has set a target for Europe to become the first climate-neutral continent by 2050 . This ambitious commitment will bring a serious challenge for the EU. However, the degree of this challenge will not be the same to all $\mathrm{EU}$ member states. In this paper, the multi-criteria decision analysis is applied to rank eight selected EU countries (Denmark, Estonia, Ireland, Latvia, Lithuania, Slovenia, Finland and Sweden) regarding GHG performance, and thus illustrate different starting points of the transition to carbon-neutrality. In parallel to the widely used indicator of GHG emissions per capita, evaluation incorporates various other criteria covering energy consumption, population size, and the use of renewable energy and fossil fuel, as well as investment and tax rates. TOPSIS analysis shows that the best GHG performance is achieved by Sweden, while Latvia ranks the lowest. The presented evaluation method could be a useful tool in planning implementation of policies to reach Green Deal settings on European, as well as on a national level.
\end{abstract}

Keywords - Country ranking; European Green Deal; greenhouse gas (GHG) emissions; TOPSIS.

\section{INTRODUCTION}

The newly introduced European Green Deal has set a particularly ambitious target for Europe to become climate-neutral by 2050. It requires to reduce $\mathrm{GHG}$ emissions by $50-55 \%$ by 2030 in comparison to the levels of 1990, and to reach net-zero GHG emissions by 2050 [1]. To clearly illustrate the ambitious extent of this target, it can be mentioned that the EU GHG emissions were reduced by $22 \%$ in 2017, compared to 1990 levels. In order to achieve full reductions up to $100 \%$ by 2050 , EU must reduce its GHG emissions by additional $78 \%$ throughout the next 30 years. Although it is determined, that emissions not mitigated by 2050 will be removed, e.g. via natural carbon sinks such as forests and carbon capture and storage technologies [2], there are still uncertainties concerning carbon storage in geological structures related to long-term leakage and safety, as well as storage in oceans due to possible negative impacts on ecology [3]. In addition, carbon storage technologies can be expensive [4]. Meanwhile, the possibilities for increasing natural carbon sequestration are ambiguous, taking into consideration the growing demand for bio resources. This confirms that the primary focus must be on reducing emissions to the maximum already at the production stage. Considering the past progress in emission reduction, introduction of the Green Deal will demand a completely new approach to the economy and quite drastic

\footnotetext{
* Corresponding author.

E-mail address: beate.zlaugotne@rtu.lv 
measures in all sectors of economy. It is clear it will possess serious challenge for all EU countries. However, it is also obvious that the starting point differs widely, bringing variations in the degree of challenge.

In this paper multi-criteria decision analysis (MCDA) is applied to determine the present position of eight selected EU countries (Denmark, Estonia, Ireland, Latvia, Lithuania, Slovenia, Finland and Sweden) in terms of GHG performance. Various indicators are applied, along with GHG emissions considering economic, political, and social and energy consumption factors. This comparison allows determining what the starting points for various countries are and which could take the lead in reaching carbon neutrality. Moreover, taking into account that countries influence each other's energy, environment and economic conditions [5], such comparison can be useful in researching the links between countries. Regarding Latvia, it gives the opportunity to detect its position compared to other EU countries and to judge on the required intensity of the necessary measures. For countries at worse GHG positions, this comparison shows the roadmap for the implementation of successful policies.

\section{Evaluation of GHG Performance}

Greenhouse gas inventory, prepared by the European Environment Agency (EEA), ranks the EU countries according to the total amount of their GHG emissions. On the EU level, progress in GHG emission reduction is mainly measured by the annual changes of the total GHG amount, changes since 1990 and (or) regarding the achievement of national targets [6]. Although, the criterion regarding carbon-neutrality achievement is net GHG emissions, implementation of various indicators allows determining how advantageous countries are in terms of GHG emission reduction.

GHG performance is often evaluated as a part of a broader environmental performance and sustainability assessments [7]-[9]. Along with direct GHG indicators, such as the total GHG emissions per country or GHG emissions per capita, such evaluations often include factors, which do not directly express the GHG emissions while still being closely related. Such factors include: the share of renewable energy [7]-[12], energy consumption [7], [8], [10], [11], environmental or energy taxes [7], [9], [10], [12], environmental protection expenditure [12] and others.

There are few studies investigating environmental indicators with the aim to evaluate GHG performance. Some are discussed below. Also, many studies have focused on the drivers of GHG emission reduction. Arguably, the most important are the increase of energy efficiency [13]-[15] and renewable energy [9], [13]. Although, [15] reported that the impact of the share of renewable energy was insignificant in GHG emission reduction, while policies to increase energy efficiency were assessed to have a greater impact.

Lately countries are often grouped into categories according to their GHG performance as an attempt to give a general demonstration of similarities and differences and search for correlations. For example, [16] established a method of four quadrants to compare the countries' performance in emission intensity, carbon removal rate, and net reduction rate of GHG emissions from 1991 to 2012. Such division is based on absolute emission quantity, as well as relative emission quantity (the ratio of GHG emissions and GDP) and trends in GHG emissions (the annual net reduction of GHG emissions). According to [16] related calculations, Latvia was the only country in the EU28 to report net GHG removal in 2012. Latvia along with other countries, including Lithuania and Estonia, was grouped in Quadrant I, representing countries with high emission intensities and high carbon removal rates. On the contrary, Germany stood out with significantly high net GHG emissions. However, due to Germany's low emission intensity it was located in Quadrant III representing countries with low emission intensities and low carbon removal rates. Quadrant II 
grouped countries representing low emission intensities and low carbon removal rates (for instance, Sweden), while Quadrant IV grouped countries with high emission intensities and low carbon removal rates (e.g. Poland).

Meanwhile, [17] grouped the EU countries into clusters according to their similarities in emissions of four types of GHG to examine the diversity of European countries in terms of GHG emissions. Four clusters regarding the application of k-means algorithm and Euclidian distance have been developed. The clusters were classified according to the amount of emissions. In this evaluation, two approaches were used - the total GHG emissions per country and the GHG emissions per capita. Grouping of the total emissions and grouping of the emissions per capita resulted in different sizes of clusters, which highlighted the question of whether countries should be evaluated by their total emissions or emissions per capita. A similar study [18] grouped countries into clusters by applying agglomeration algorithm. In other investigations [15], [16], [18] countries were evaluated by a narrow set of indicators, and the purpose of such evaluations was to group countries rather than to compare to each other in order to assess the best and the worst performances. The aim of this paper is to rank the selected EU countries according to their GHG performance by offering a set of economic, political, and social indicators.

\section{GHG Emission Profile of The Selected EU Countries}

For the comparison of GHG performance, eight EU countries have been selected, ensuring that different national environmental, economic and political backgrounds are covered. The main point of reference for selecting countries for comparison was the GHG intensity of energy consumption. Latvia was chosen as the main focus of analysis, alongside Ireland and Slovenia, classified as medium GHG intense. Estonia and Lithuania were selected as the countries with high GHG intensity, whereas Finland, Denmark and Sweden were chosen to represent countries with relatively low GHG intensity.

Eurostat data analysis from 2005 to 2015 indicates that Estonia had the highest average GHG emissions per capita (15.2 $\mathrm{t} \mathrm{CO}_{2}$ eq./capita) (Fig. 1), followed by Ireland (14.4 t CO 2 eq./capita), while the lowest GHG emissions were achieved by Latvia $\left(5.7 \mathrm{t} \mathrm{CO}_{2}\right.$ eq./capita), Sweden $(6.7 \mathrm{t}$ $\mathrm{CO}_{2}$ eq./capita) and Lithuania (7.1 $\mathrm{t} \mathrm{CO}_{2}$ eq./capita).

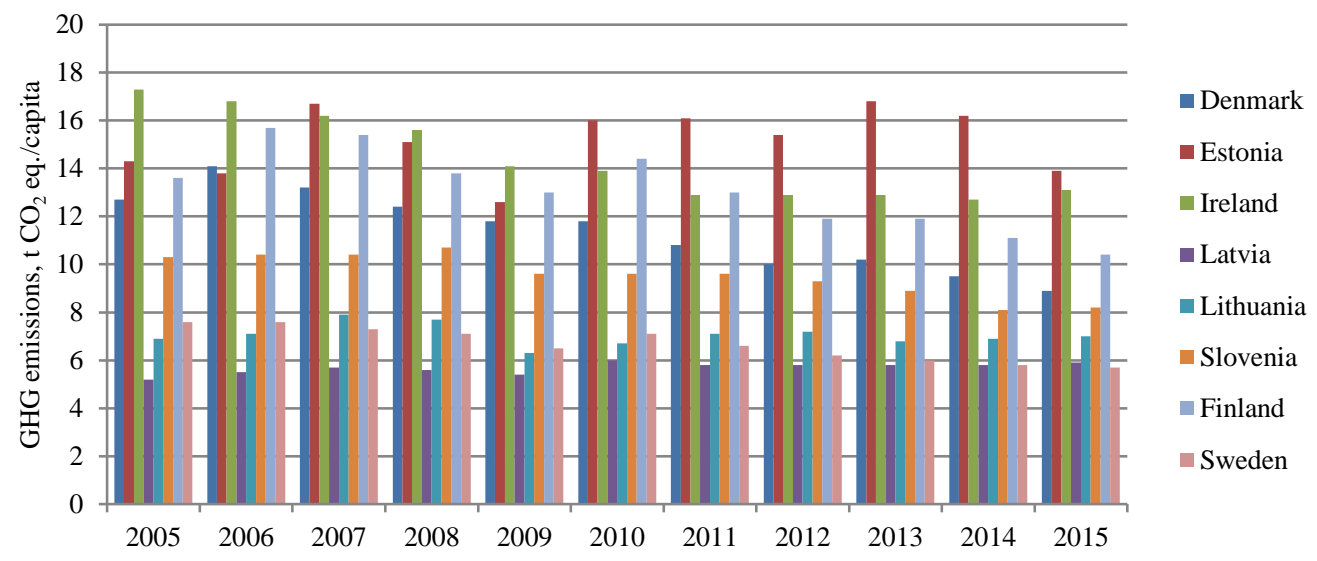

Fig. 1. GHG emissions per capita. 
During the studied period, Sweden had the best performance regarding renewable energy consumption. All countries have made improvements in the share of renewable energy. Some countries such as Sweden, Finland, and Denmark have made improvements by more than $10 \%$ in a 10 -year-period.

In terms of environmental taxes, Denmark had the highest performance. Denmark has the second highest tax rate in the EU energy sector. Slovenia has been approaching Denmark's environmental tax revenues since 2012, as Slovenia has higher tax rate on transport fuels than on fuels used for energy production - heating or electricity.

From all selected countries, Estonia has the highest $\mathrm{CO}_{2}$ emissions, which is the second highest value in the EU after Luxembourg. The main reason for the high emissions in Estonia is electricity production from oil shale, which accounts for about $90 \%$ of the total $\mathrm{CO}_{2}$ pollution, and recently oil shale has also been used for liquid fuel (diesel) production [19]. However, Estonia has set ambitious goals to increase electricity production from biomass [20]. Ireland is also a significant source of $\mathrm{CO}_{2}$ emissions with most of the emissions coming from industry and agriculture [21], and Finland, where emissions from energy sector are mainly generated by utilization of natural gas and peat [22]. Overall, in a 10-year-period, emissions are decreasing periodically, except for Estonia where the trend is uneven.

The total consumption of solid fossil fuel is low in Estonia, Latvia and Lithuania in comparison to other selected countries. Generally, the consumption of solid fossil fuels is decreasing. Finland stands out with significantly high values for this indicator because over half of its heat is generated from solid fossil fuels.

Households hold an important position in the total energy consumption and represent the overall energy consumption image of a population. Household energy consumption per capita is the lowest in Lithuania, while Finland scores the highest. All the selected countries have reduced their household energy consumption over recent years.

Eurostat data indicates that the investment share of GDP was high during a period from 2005 to 2008 for all selected countries, and in 2009 it decreased by $10 \%$ on average, which can be related to the global financial crisis. However, the investment share for all countries started to increase afterwards. The highest average investment share was in Estonia $(28.5 \%)$.

\section{Methodology}

\subsection{Methodology Algorithm}

The evaluation process consisted of four main steps (Fig. 2). First, eight EU countries for the comparison have been selected. Next, criteria for GHG performance evaluation have been chosen, followed by the determination of their importance with the application of AHP (Analytic hierarchy process). Lastly, the ranking of countries' GHG performance was made using the TOPSIS method.

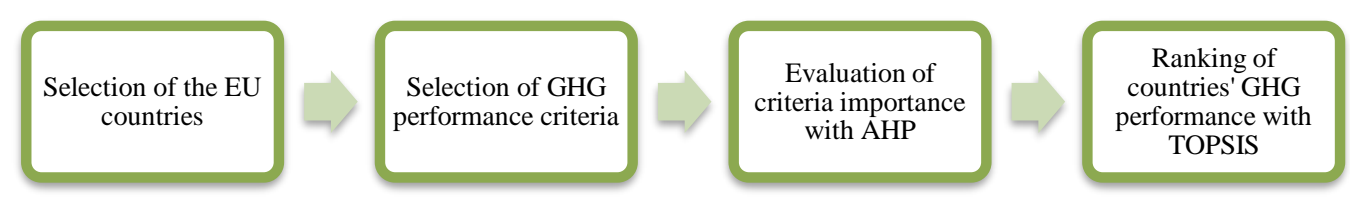

Fig. 2. Methodology algorithm. 
MCDA (Multi-criteria decision analysis) is a set of processes by which problems are solved, when problems, alternatives and criteria are defined. There are dozens of methods for calculating the best alternatives, according to a set of criteria. Because of the opportunity to easily compare different alternatives, TOPSIS (Technique for Order Preference by Similarity to Ideal Solutions) method was chosen for this evaluation. The basic principle is that the best alternative is at the shortest distance to the ideal solution and at the furthest distance to the negative-ideal solution [23]. As far as the TOPSIS method is concerned, it is important to define the best and the worst values for criteria. The best alternative is the one with the highest value.

AHP (Analytic hierarchy process) was developed by Thomas L. Saaty. It is one of the most popular methods used for finding criteria weight. With this method, all criteria are listed and then compared pair-wise according to their importance (contribution to reaching an objective) [24]. All criteria are compared to each other assigning values from 1 to 9 . After calculations, each criterion has a weight and is further used in ranking alternatives.

\subsection{Selection of Criteria}

Based on the information provided in literature, as well as considering the available data, six criteria were chosen for the evaluation of GHG performance (Fig. 3). GHG emissions per capita were chosen as a widely used indicator in many studies and EU reports, as well as a basic representative factor of countries' emissions level. Income from environmental taxes was selected as an indicator representing the overall role of environmental protection in the national tax system, expressed as a percentage of the total income from taxes. Household energy consumption per capita was expressed as $\mathrm{kg}$ of oil equivalent, and it allowed to easily compare the energy needs of population.

Investment share of GDP is an indicator used to monitor progress towards EU Sustainable Development Goals and represents the level of economic productivity. Consumption of solid fossil fuels was chosen as a basic representative of the amount of the main GHG generating fuels, and was expressed in absolute values of thousand tonnes. Last, renewable energy consumption represents the achievements towards clean energy, and was expressed as a share of consumed renewable energy in gross final energy consumption.

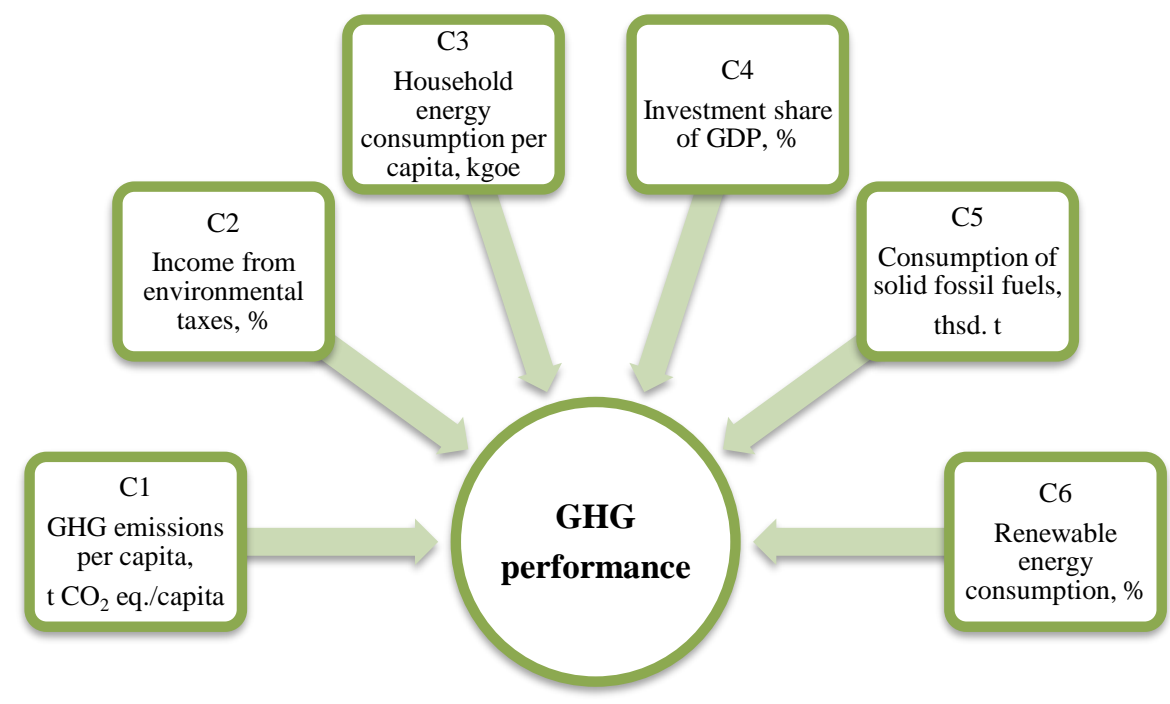

Fig. 3. GHG performance criteria. 


\subsection{Evaluation of Criteria Weight}

After defining criteria, their weight was evaluated. All criteria were compared in pairs and attributed with values on a scale from 1 to 9 , where 1 means that the criteria are equally important and 9 means that one criterion is absolutely more important than the other comparable criterion. Criteria weights were determined with expert judgement method. Two experts of the environmental science participated in the evaluation process. The mean values from expert judgements can be seen in Table 1 .

Criterion with the highest attributed importance was GHG emissions per capita (32\%), while all other criteria were significantly less important. In addition, Table 1 indicates the desired direction for criteria values. Minimal values are desired for GHG emissions, energy consumption, investment from GDP and solid fuel consumption criteria, while the maximal values are desired for income from environmental taxes and renewable energy consumption. AHP analysis gave a consistency index (CI) of 0.118 and consistency ratio (CR) of 0.095 indicating that the pair-wise comparisons are consistent.

TABLE 1. CRITERIA WEIGHTS

\begin{tabular}{llll}
\hline Criteria & Weight & Best values \\
\hline C1 & Greenhouse gas (GHG) emissions per capita & $32 \%$ & MIN \\
C2 & Income from environmental taxes & $19 \%$ & MAX \\
C3 & Household energy consumption per capita & $15 \%$ & MIN \\
C4 & Investment share of GDP & $13 \%$ & MIN \\
C5 & Solid fuel consumption & $13 \%$ & MIN \\
C6 & Renewable energy consumption & $8 \%$ & MAX \\
\hline
\end{tabular}

The statistical indicator values for each country were obtained from Eurostat database for a time period from 2005 to 2015. Data were normalised after MIN-MAX normalisation. Input data for TOPSIS is presented in Table 2.

TABLE 2. TOPSIS INPUT DATA

\begin{tabular}{|c|c|c|c|c|c|c|c|c|c|}
\hline & & A1 & A2 & $\mathbf{A 3}$ & A4 & A5 & A6 & A7 & A8 \\
\hline & & Denmark & Estonia & Ireland & Latvia & Lithuania & Slovenia & Finland & Sweden \\
\hline $\mathrm{C} 1$ & $\begin{array}{l}\text { Greenhouse } \\
\text { gas (GHG) } \\
\text { emissions per } \\
\text { capita }\end{array}$ & 0.481 & 0.613 & 0.760 & 0.602 & 0.472 & 0.559 & 0.741 & 0.517 \\
\hline $\mathrm{C} 2$ & $\begin{array}{l}\text { Income from } \\
\text { environmental } \\
\text { taxes }\end{array}$ & 0.282 & 0.500 & 0.797 & 0.494 & 0.273 & 0.527 & 0.614 & 0.565 \\
\hline $\mathrm{C} 3$ & $\begin{array}{l}\text { Household } \\
\text { energy } \\
\text { consumption } \\
\text { per capita }\end{array}$ & 0.552 & 0.432 & 0.575 & 0.632 & 0.615 & 0.558 & 0.411 & 0.573 \\
\hline $\mathrm{C} 4$ & $\begin{array}{l}\text { Investment } \\
\text { share of GDP }\end{array}$ & 0.420 & 0.470 & 0.442 & 0.419 & 0.355 & 0.412 & 0.466 & 0.319 \\
\hline $\mathrm{C} 5$ & $\begin{array}{l}\text { Solid fossil } \\
\text { fuel } \\
\text { consumption }\end{array}$ & 0.475 & 0.469 & 0.382 & 0.615 & 0.484 & 0.696 & 0.435 & 0.612 \\
\hline C6 & $\begin{array}{l}\text { Renewable } \\
\text { energy } \\
\text { consumption }\end{array}$ & 0.434 & 0.530 & 0.465 & 0.445 & 0.388 & 0.549 & 0.421 & 0.539 \\
\hline
\end{tabular}




\section{Results}

Results of the TOPSIS analysis indicate that the best GHG performance is reached by Sweden, which achieved a coefficient of 0.64 (Table 3). Sweden was expected to rank first, as it has showed high performance in other studies evaluating sustainability and environmental performance (e.g. [9] and [11]). Also, it has one of the lowest GHG emissions per capita and the share of renewable energy is one of the highest as well. Regarding other indicators, Sweden reached average score, except for solid fossil fuel consumption, where it takes the second worst place. Although, it is noteworthy that solid fossil fuel consumption is an absolute value, and therefore Sweden's poor performance for this indicator may be explained by the size of its population and industry or other factors related to consumption of resources.

TABLE 3. RESUlting COUNTRY COEFFICIENTS

\begin{tabular}{llllllll}
\hline Denmark & Estonia & Ireland & Latvia & Lithuania & Slovenia & Finland & Sweden \\
\hline A1 & A2 & A3 & A4 & A5 & A6 & A7 & A8 \\
0.463 & 0.497 & 0.538 & 0.424 & 0.457 & 0.499 & 0.481 & 0.644 \\
6 & 4 & 2 & 8 & 7 & 3 & 5 & 1 \\
\hline
\end{tabular}

Despite the highest GHG emissions per capita, Ireland ranks second in GHG performance evaluation (Fig. 4). Ireland's relatively good performance can be explained by its outstandingly high score for the income from environmental taxes, which was the second most important criterion, as well as the significantly low consumption of solid fossil fuels.

Meanwhile, Latvia showed the lowest GHG performance. The main reason for that could be the significantly high score for household energy consumption per capita, where Latvia holds the worst position. Consumption of solid fossil fuels plays a relatively important role as well, while other indicator values were considered rather average.

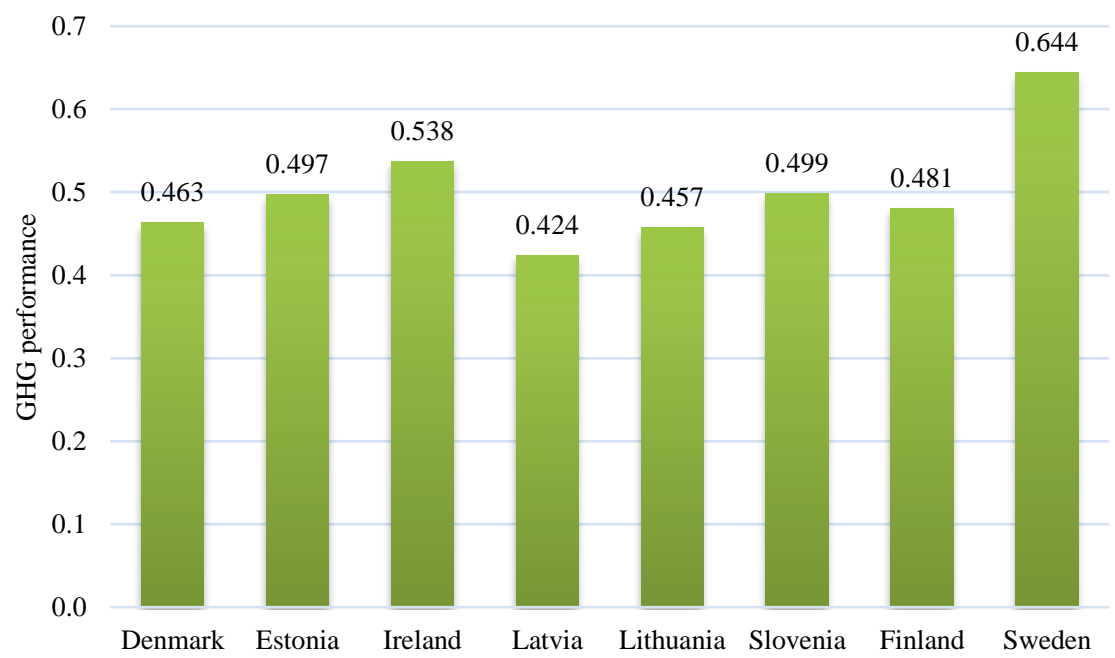

Fig. 4. Ranking of countries' GHG performance.

However, it is important to consider that evaluations were made from the average values for a period from 2005 to 2015, therefore, development trends of indicator values were not considered. 
For example, the share of income from environmental taxes in Latvia has a lower indicator value than Ireland, while, in 2015, Latvia had a share of environmental taxes of $3.52 \%$ and Ireland had a share of $1.88 \%$ from GDP.

Denmark ranks nearly the second worst in GHG performance ranking. Denmark had average values for most of the criteria, without taking any top or bottom positions. However, its score decreased because of the low share of income from environmental taxes.

The results indicate that Estonia and Slovenia perform almost equally in terms of GHG performance. Both countries have similar values for most indicators. Nevertheless, Slovenia has higher household energy consumption and solid fossil fuel consumption, while Estonia has the second lowest household energy consumption per capita.

In the performed GHG ranking, Lithuania takes the second worst place, achieving slightly higher coefficient than Latvia. This result is somewhat surprising, considering that Lithuania had the best score for GHG emissions per capita, which is an indicator of significantly high importance. Still, Lithuania performs the worst for the share of income from environmental taxes and renewable energy consumption which arguably results in the low overall GHG performance.

\section{CONCLuSion}

The aim of the paper was to rank selected EU countries according to their GHG performance. Several indicators were implemented, covering aspects of energy consumption, as well as considering political (environmental taxes), economic (investment) and social (population size) factors. The ranking was performed with TOPSIS method, which allowed a simple comparison of the criteria.

Results indicate that from all the compared countries Sweden is at the most desired position in terms of GHG performance and has the most promising starting point to achieve carbon-neutrality by 2050 . Sweden had relatively good values for the most of the selected criteria, and therefore its implemented policies could work as an example for other countries.

Despite the fact that Latvia performs rather well in many environmental and sustainability assessments of the EU countries (e.g. [10] and [15]), results show that it holds the lowest position in terms of GHG performance in comparison to the other selected EU countries. This indicates that achievement of carbon neutrality by 2050 will be a particular challenge to Latvia. Results suggest that one of the focus points for Latvia should be reducing its energy consumption, which, arguably, can be achieved by increasing energy efficiency.

Although some countries perform better than others in terms of GHG performance, it has been highlighted that the current policies will only reduce EU's GHG emissions by $60 \%$ by 2050 [1], therefore, all countries need to take drastic measures in reorganizing their policies to achieve clean energy and sustainable economy.

Further studies should arguably focus on:

- Implementation of additional indicators to arrive at a more precise countries' ranking;

- Application of quantitative data for the determination of criteria weights;

- Application of methods that allow to investigate connections between indicators, thus revealing the necessary focuses for policy development;

- Consideration of the past progress of indicator values, which would make the evaluation more future-oriented.

With the above-mentioned and other slight improvements, the presented GHG performance evaluation could be a useful tool in planning the implementation of policies to reach the Green Deal settings on European, as well as on a national level. 


\section{ACKNOWLEDGEMENT}

The research is funded by the Ministry of Economics of the Republic of Latvia, project "Assessment of Latvia's renewable energy supply-demand economic potential and policy recommendations”, Project No. VPP-EM-2018/AER-1-0001.

\section{REFERENCES}

[1] European Commission. The European Green Deal. Communication from the Commission to the European Parliament, the European Council, the Council, the European Economic and Social Committee and the Committee of the Regions. Brussels, 2019.

[2] European Commission. Clean energy. The European Green Deal. 2019.

[3] Lee H. Climate Change Biology, $1^{\text {st }}$ ed. Academic Press, 2010.

[4] Lal R. Carbon sequestration. Philosophical Transactions of the Royal Society B 2008:363(1492):815-830. https://doi.org/10.1098/rstb.2007.2185

[5] Bajcinovci B. Environment quality: Impact from traffic, power plant and land morphology, a case study of Prishtina. Environmental and Climate Technologies 2017:19(1):65-74. https://doi.org/10.1515/rtuect-2017-0006

[6] Danila A. M., et al. Annual European Union greenhouse gas inventory $1990-2016$ and inventory report 2018. Copenhagen: EEA, 2018.

[7] Luzzati T., Gucciardi G. A non-simplistic approach to composite indicators and rankings: An illustration by comparing the sustainability of the EU Countries. Ecological Economics 2015:113:25-38. https://doi.org/10.1016/j.ecolecon.2015.02.018

[8] Antanasijević D., et al. A differential multi-criteria analysis for the assessment of sustainability performance of European countries: Beyond country ranking. Journal of Cleaner Production 2017:165:213-220. https://doi.org/10.1016/j.jclepro.2017.07.131

[9] Moutinho V., Madaleno M., Robaina M. The economic and environmental efficiency assessment in EU cross-country: Evidence from DEA and quantile regression approach. Ecological Indicators 2017:78:85-97. https://doi.org/10.1016/j.ecolind.2017.02.042

[10] García-Álvarez M. T., Moreno B., Soares I. Analyzing the sustainable energy development in the EU-15 by an aggregated synthetic index. Ecological Indicators 2016:60:96-1007. https://doi.org/10.1016/j.ecolind.2015.07.006

[11] Siksnelyte I., Zavadskas E. K., Bausys R., Streimikiene D. Implementation of EU energy policy priorities in the Baltic Sea Region countries: Sustainability assessment based on neutrosophic MULTIMOORA method. Energy Policy 2018:125:90-102. https://doi.org/10.1016/j.enpol.2018.10.013

[12] Cucchiella F., et al. A comparison of environmental and energetic performance of European countries: A sustainability index. Renewable and Sustainable Energy Reviews 2017:78:401-413. https://doi.org/10.1016/j.rser.2017.04.077

[13] De Alegría I. M., et al. Spain's fulfillment of its Kyoto commitments and its fundamental greenhouse gas (GHG) emission reduction drivers. Renewable and Sustainable Energy Reviews, 2016:59:858-867. https://doi.org/10.1016/j.rser.2015.12.208

[14] Cruz L., Dias J. Energy and $\mathrm{CO}_{2}$ intensity changes in the EU-27: Decomposition into explanatory effects. Sustainable Cities and Society 2016:26:486-495. https://doi.org/10.1016/j.scs.2016.03.007

[15] Štreimikiene D., Balezentis T. Kaya identity for analysis of the main drivers of GHG emissions and feasibility to implement EU '20-20-20' targets in the Baltic States. Renewable and Sustainable Energy Reviews 2016:58:11081113. https://doi.org/10.1016/j.rser.2015.12.311

[16] Su M., et al. Greenhouse gas emission accounting for EU member states from 1991 to 2012. Applied Energy 2016:184:759-768. https://doi.org/10.1016/j.apenergy.2016.02.074

[17] Kijewska A., Bluszcz A. Research of varying levels of greenhouse gas emissions in European countries using the kmeans method. Atmospheric Pollution Research. 2016:7(5):935-944. https://doi.org/10.1016/j.apr.2016.05.010

[18] Kijewska A., Bluszcz A. Analysis of greenhouse gas emissions in the European Union member states with the use of an agglomeration algorithm. Journal of Sustainable Mining 2016:15(4):133-142. https://doi.org/10.1016/j.jsm.2017.02.001

[19] Randma T. Estonia needs a plan and support to get rid of its dirty oil shale. Energy Post, 2018.

[20] Volkova A., Latosov E., Siirde A. Heat Storage Combined with Biomass CHP under the National Support Policy. A Case Study of Estonia. Environmental and Climate Technologies 2020:24(1):171-184. https://doi.org/10.2478/rtuect$\underline{2020-0011}$

[21] O’Sullivan K. Ireland has third highest emissions of greenhouse gas in EU. The Irish Times, 2019.

[22] Statistics Finland. Greenhouse gas emissions increased, emission allocation exceeded. Environmental and natural Resources 2019. Helsinki, 2019.

[23] Opricovic S., Tzeng G. H. Compromise solution by MCDM methods: A comparative analysis of VIKOR and TOPSIS. European Journal of Operational Research 2004:156(2):445-455. https://doi.org/10.1016/S0377-2217(03)00020-1 
[24] Leal J. E. AHP-express: A simplified version of the analytical hierarchy process method. MethodsX 2020:7:100748. https://doi.org/10.1016/j.mex.2019.11.021
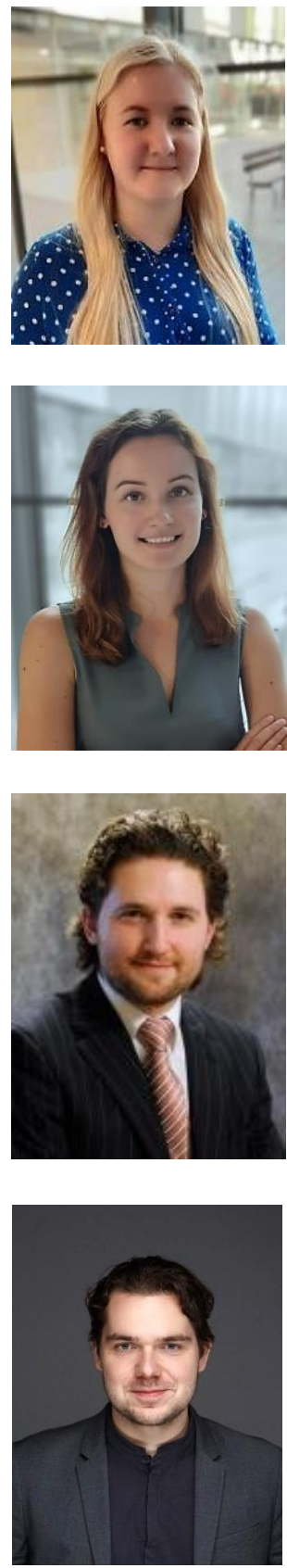

Beate Zlaugotne, M. sc. ing. student, research assistant at RTU Institute of Energy Systems and Environment (IESE). The main areas of research are the analysis of multi-criteria decisions and the use of renewable energy sources and their alternatives.

E-mail: Beate.Zlaugotne@rtu.lv

Linda Ievina, M. Sc. env. works as a researcher at Institute of Energy Systems and Environment, Riga Technical University. Her research interests are related to renewable energy and sustainable use of resources, as well as the application of geographic information systems in energy development planning. Currently she is working on her $\mathrm{PhD}$ thesis on the spatial distribution of renewable energy sources in Latvia.

E-mail: Linda.Ievina@rtu.lv

Denis Baranenko graduated with honours from the Saint-Petersburg State University of Refrigeration and Food Engineering (later - Institute of Refrigeration and Biotechnologies, ITMO University) in 2003. He received the $\mathrm{PhD}$ degree from the same university in 2006.

Since 2006 works there as an associate professor, from 2011 directed the work of a research laboratory, from 2014 heads the International research centre "Biotechnologies of the Third Millennium".

Research interests: resource and energy saving food biotechnologies, biologically active compounds, functional food products.

E-mail: denis.baranenko@niuitmo.ru

Reinis Azis, M. sc. He has received his Bachelor's degree in the field of international politics, Master's degree in the field of environmental science in Riga Technical University, Latvia (2017) and since 2017 is a $\mathrm{PhD}$ student of environmental science in Riga Technical University, Faculty of Electrical and Environmental Engineering. Reinis Azis works in Investment and Development Agency of Latvia - since 2018 as a Representative Office Head in the United Kingdom, now as a Deputy Director in Latvia. Research interests: energy politics, innovative technologies, financial instruments and technology development. E-mail: reinis.azis@gmail.com 


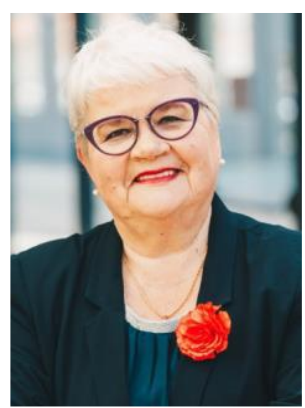

Dagnija Blumberga, Dr. habil. sc. ing., professor, director of the Institute of Energy Systems and Environment, Riga Technical University. Her two-step doctoral degree "Condensing Unit" was defended in Lithuanian Energy Institute, Kaunas (1988). Doctor Habilitus Thesis "Analysis of Energy Efficiency from Environmental, Economical and Management Aspects" was prepared in Royal Institute of Technology (KTH) Stockholm (1995) and was defended in Riga Technical University (1996).

Dagnija Blumberga has been part of academic staff of Riga Technical University since 1976 and director of Institute of Environmental Protection and Energy Systems since 1999.

The main research area is renewable energy resources. She has participated in different local and international projects related to energy and environment as well as an author of more than 200 publications and 14 books.

E-mail: dagnija.blumberga@rtu.lv

ORCID iD: https://orcid.org/0000-0002-9712-0804 